\title{
Article \\ Species Phylogeny versus Gene Trees: A Case Study of an Incongruent Data Matrix Based on Paphiopedilum Pfitz. (Orchidaceae)
}

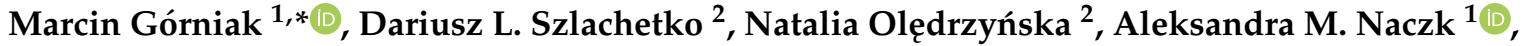 \\ Agata Mieszkowska ${ }^{1}$, Lidia Boss ${ }^{3}$ (D) and Marek S. Ziętara ${ }^{1}$
}

1 Department of Evolutionary Genetics and Biosystematics, University of Gdańsk, 80-309 Gdańsk, Poland; aleksandra.naczk@ug.edu.pl (A.M.N.); agata.mieszkowska@ug.edu.pl (A.M.); marek.zietara@ug.edu.pl (M.S.Z.)

2 Department of Plant Taxonomy and Nature Conservation, University of Gdańsk, 80-309 Gdańsk, Poland; dariusz.szlachetko@ug.edu.pl (D.L.S.); natalia.oledrzynska@ug.edu.pl (N.O.)

3 Department of Bacterial Molecular Genetics, University of Gdańsk, 80-309 Gdańsk, Poland; lidia.boss@ug.edu.pl

* Correspondence: marcin.gorniak@ug.edu.pl

\section{check for}

updates

Citation: Górniak, M.; Szlachetko, D.L.; Olędrzyńska, N.; Naczk, A.M. Mieszkowska, A.; Boss, L.; Ziętara, M.S. Species Phylogeny versus Gene Trees: A Case Study of an Incongruent Data Matrix Based on Paphiopedilum Pfitz. (Orchidaceae). Int. J. Mol. Sci. 2021, 22, 11393. https://doi.org/10.3390/ ijms222111393

Academic Editor: Salvatore Saccone

Received: 14 September 2021

Accepted: 20 October 2021

Published: 21 October 2021

Publisher's Note: MDPI stays neutral with regard to jurisdictional claims in published maps and institutional affiliations.

Copyright: (c) 2021 by the authors. Licensee MDPI, Basel, Switzerland. This article is an open access article distributed under the terms and conditions of the Creative Commons Attribution (CC BY) license (https:// creativecommons.org/licenses/by/ $4.0 /)$
Abstract: The phylogeny of the genus Paphiopedilum based on the plastome is consistent with morphological analysis. However, to date, none of the analyzed nuclear markers has confirmed this. Topology incongruence among the trees of different nuclear markers concerns entire sections of the subgenus Paphiopedilum. The low-copy nuclear protein-coding gene PHYC was obtained for 22 species representing all sections and subgenera of Paphiopedilum. The nuclear-based phylogeny is supported by morphological characteristics and plastid data analysis. We assumed that an incongruence in nuclear gene trees is caused by ancestral homoploid hybridization. We present a model for inferring the phylogeny of the species despite the incongruence of the different tree topologies. Our analysis, based on six low-copy nuclear genes, is congruent with plastome phylogeny and has been confirmed by phylogenetic network analysis.

Keywords: homoploid hybridization; nuclear genes; concatenation; molecular dating; Orchidaceae; Paphiopedilum

\section{Introduction}

In recent years, nuclear genome data (often obtained using new sequencing methods) have shown discrepancies among phylogenetic trees based on various markers. Tree topology conflicts can be explained either by hybridization or incomplete lineage sorting (ILS) [1]. The latter stems from incomplete random sorting of alleles at many loci, independently, due to short intervals. Maddison [2] proposed minimizing deep coalescences (MDC) as an optimization criterion for inferring the species tree from a set of incongruent gene trees. It was assumed in that paper that ILS was the only reason for the discrepancy between topologies [2]. In order to determine which of the aforementioned processes may be responsible for incongruence in tree topologies, analyses based on the molecular clock were applied [3], in addition to gene coalescence time analysis for a selected group [3,4]. Determining the coalescence time of a particular molecular marker, compared with species divergence time, enables the elimination of ILS as a factor influencing the topology of the phylogenetic tree [3]. However, determining the real coalescence time requires knowledge of the effective population size, ancestor, and generation time factors, which are unknown for many groups. Distinguishing between hybridization and ILS is based on the fact that the latter is a random process that stems from the nature of allele sorting. In contrast, hybridization is not random, and it shortens the genetic distance between species within the introduced markers. Differences between those processes have been used in order to 
identify them [5]. However, the distinction between these processes requires the analysis of many loci. As the history of many groups is highly reticulate, methods have been developed that include both ILS and hybridization [6,7]. Here, we used multiple nuclear and plastid markers with multispecies coalescent methods and time divergence analysis to understand the processes that gave rise to the lineage of the Asiatic genus Paphiopedilum. We also explain the reason for the conflict in the phylogenetic tree topologies constructed on the basis of nuclear markers.

For the purpose of this article, the taxonomy of the genus Paphiopedilum proposed by Cribb [8] was used. This Asiatic genus was established by Pfitzer in 1886. It is one of five genera within the subfamily Cypripedioideae (=Cypripediaceae). The intrageneric division of Paphiopedilum is based mainly on floral morphology and leaf types [8-13]. Plastid DNA analyses [14-16] strongly support the infrageneric approach (based on morphological characters) proposed by Cribb [8], which distinguishes three independent evolutionary lineages-namely, three monophyletic clades, corresponding to the subgenera Parvisepalum, Brachypetalum, and Paphiopedilum. Relationships between sections in the subgenus Paphiopedilum was also confirmed by analysis of plastid DNA [14-16], which revealed the existence of two evolutionary lineages-one including single-flowered species (sections Barbata and Paphiopedilum) and the other including multi-flowered ones (i.e., sections Coryopedilum, Pardalopetalum, and Cochlopetalum). This was also confirmed by analysis of the plastome [17]. It is worth noting that the currently accepted phylogeny, reconstructed based on plastid data, is supported by morphological data [14], yet it seems not to be supported by nuclear genes researched to date. The XDH [15] marker indicates that section Paphiopedilum and all three multi-flowered sections are sister groups, which is also true for the LFY [16] marker with the exception of section Cochlopetalum-LFY supports Cochlopetalum being a sister group of section Barbata. On the other hand, RAD51 [16] indicates that section Cochlopetalum is sister to all other sections of the subgenus Paphiopedilum. None of the aforementioned nuclear markers (i.e., the markers $L F Y, X D H$, and RAD51) supports subgenus Paphiopedilum, and while the ACO and DEF4 nuclear markers indeed support it strongly [16], they do not resolve relationships (polytomy) within this taxon. It is worth noting that tree topology incongruence of different nuclear markers $[15,16]$ in the subgenus Paphiopedilum concerns sections Barbata and Cochlopetalum.

\section{Results}

\subsection{Molecular Clock Phylogeny}

Bayes Factors between different clock models of data matrices, statistics for one of the most parsimonious trees, and MrModelTest results are shown in Table 1, Table 2 and Table S1, respectively. In all analyses, the species of the subgenus Parvisepalum were sister to all the remaining species of the genus (Figures 1 and S1-S4). The XDH, LFY, and RAD51 markers (Figure 1a-c, respectively) treated separately do not support subgenus Paphiopedilum, whose sections were intermixed with species of subgenus Brachypetalum. PHYC analysis supported subgenus Paphiopedilum only moderately (Posterior Probabilities $(\mathrm{PP})=0.98$ ), (16.4 Ma, 95\% Highest Posterior Density (HPD): 11.1-22.1) (Figure 1d). Individual analyses of all the mentioned markers (XDH, LFY, RAD51, PHYC) showed incongruence between trees, in relation to entire sections of subgenus Paphiopedilum (sections Barbata and Cochlopetalum). In XDH analysis (Figure 1a), multi-flowered species (PP = 0.89), (8.5 Ma, 95\% HPD: 5.3-12.9) (sections Coryopedilum, Pardalopetalum, Cochlopetalum) were sister to the nominal one (PP = 1.0), (10.3 Ma, 95\% HPD: 6.4-15.1). Section Barbata and subgenus Brachypetalum were in a polytomy with the above-mentioned sections. In $L F Y$ tree analysis (Figure 1b), Coryopedilum and Pardalopetalum were sister to Paphiopedilum ( $\mathrm{PP}=0.98$ ), (16.7 Ma, 95\% HPD: 13.3-20.7), and section Barbata was sister to section Cochlopetalum (PP = 1.0), (14.6 Ma, 95\% HPD: 11.6-18.3). In RAD51 tree analysis (Figure 1c), Coryopedilum and Pardalopetalum were sister to Paphiopedilum and Barbata sections (PP $=1.0),(10 \mathrm{Ma}, 95 \%$ HPD: 7.1-13.2). Cochlopetalum was sister to subgenus Brachypetalum, although lacks support $(\mathrm{PP}=0.86),(10.77 \mathrm{Ma}, 95 \% \mathrm{HPD}: 7.41-14.55)$. In PHYC analysis (Figure 1d), Coryopedilum 
with Pardalopetalum and Cochlopetalum (PP = 1.0), (11.69 Ma, 95\% HPD: 7.1-16.78) were sister to Paphiopedilum with Barbata (PP = 1.0), (9.4 Ma, 95\% HPD: 5.0-14.8). A similar topology was obtained in the analysis of the combined plastid data (Figure 1i). Both analyses (PHYC and combined plastid) are congruent with morphological analysis [14].

Table 1. Bayes factors between different clock models of data matrices.

\begin{tabular}{|c|c|c|c|c|}
\hline Data Matrix & Model Comparison & Log Marginal Likelihood & Bayes Factor (2 BF) & Evidence against $\mathbf{H}_{0}$ \\
\hline$A C O$ & Relaxed/B and D \# vs. Strict/B and D* & -4499.32 vs. -4496.78 & 5.08 & Weak \\
\hline DEF4 & Relaxed/B and D \# vs. Strict/B and D* & -3701.28 vs. -3700.92 & 0.72 & Inconclusive \\
\hline PHYC & Relaxed/B and D \# vs. Strict/B and D* & -1665.58 vs. -1662.93 & 5.3 & Weak \\
\hline$X D H$ & Relaxed/B and D \# vs. Strict/B and D * & -2143.99 vs. -2143.49 & 1.0 & Inconclusive \\
\hline$L F Y$ & Strict/B and D \# vs. Relaxed/B and D* & $-12,001.96$ vs. $-11,972.86$ & 58.2 & Very strong \\
\hline RAD51 & Relaxed/B and D \# vs. Strict/B and D* & -2908.64 vs. -2906.61 & 4.06 & Weak \\
\hline plastid & Strict/B and D \# vs. Relaxed/B and D * & $-15,868.13$ vs. $-15,848.6$ & 39.06 & Very strong \\
\hline
\end{tabular}

$\mathrm{B}$ and $\mathrm{D}$ - the birth-death process; \#- $\mathrm{H}_{0}$, the null hypothesis (with lower marginal likelihood); ${ }^{-}$-selected model.

Table 2. Statistics of one of the parsimonious trees.

\begin{tabular}{|c|c|c|c|c|c|c|c|c|c|c|}
\hline Matrix & $A C O$ & $D E F 4$ & $A C O / D E F 4$ & PHYC & $X D H$ & $L F Y$ & $R A D 51$ & $\begin{array}{c}X D H / L F Y / \\
\text { RAD51/ } \\
P H Y C\end{array}$ & Plastid & $\begin{array}{l}\text { Nuclear } \\
\text { Combined } \\
\text { Referring } \\
\text { to Table } 1\end{array}$ \\
\hline No. of taxa & 22 & 23 & 21 & 23 & 23 & 21 & 23 & 20 & 23 & 19 \\
\hline $\begin{array}{l}\text { Included positions in } \\
\text { matrix }\end{array}$ & 1393 & 1241 & 2634 & 799 & 909 & 3368 & 892 & 5948 & 8731 & 13,117 \\
\hline Variable site & 296 & 246 & 518 & 55 & 101 & 862 & 193 & 1154 & 442 & 2093 \\
\hline $\begin{array}{c}\text { Parsimony- } \\
\text { uninformative sites }\end{array}$ & 163 & 128 & 281 & 21 & 63 & 377 & 113 & 581 & 182 & 1270 \\
\hline $\begin{array}{c}\text { Parsimony- } \\
\text { informative sites }\end{array}$ & 133 & 118 & 237 & 34 & 38 & 485 & 80 & 573 & 260 & 823 \\
\hline Consistency index (CI) & 0.9 & 0.95 & 0.91 & 0.9 & 0.95 & 0.8 & 0.88 & 0.8 & 0.88 & 0.9 \\
\hline Retention index (RI) & 0.88 & 0.95 & 0.89 & 0.94 & 0.96 & 0.79 & 0.86 & 0.79 & 0.91 & 0.82 \\
\hline
\end{tabular}

The combined analysis of the four markers (XDH/LFY/RAD51/PHYC-Figure 1e) strongly supports subgenus Paphiopedilum $(\mathrm{PP}=1.0)$, indicating a common origin of its species and its monophyly. Its tMRCA (time to the Most Recent Common Ancestor) in this analysis equaled 13.3 Ma (95\% HPD: 10.0-16.9). On the other hand, exclusion of RAD51 from the analysis changed tMRCA to 17.6 Ma (95\% HPD:13.4-21.86) (Figure 1f). Conversely, the $A C O$ (Figure $1 \mathrm{~g}$ ) and DEF4 (Figure $1 \mathrm{~h}$ ) markers strongly support $(\mathrm{PP}=1.0)$ subgenus Paphiopedilum, both when treated separately and in the combined analysis (Figure 1j). Separately, they produced the following tMRCA results: $12.67 / 11.6 \mathrm{Ma}$, respectively, (95\% HPD: 9.6-16.3/8.4-15.1) (Figure 1g,h), while the combined analysis of these markers indicated 11.7 Ma (95\% HPD: 9.1-14.6) (Figure 1j), in accordance with the combined plastid marker analysis (11.2 Ma, 95\% HPD: 6.83-16.3) (Figure 1i). A multi-flowered species clade (Coryopedilum with Pardalopetalum and Cochlopetalum) and single-flowered species clade (Paphiopedilum and Barbata) were not supported by ACO,DEF4, and ACO/DEF4 analysis (polytomy occurred). Plastid data analysis strongly supported both of the above-mentioned clades $(\mathrm{PP}=1.0 ; 10 \mathrm{Ma}, \mathrm{PP}=1.0 ; 8.8 \mathrm{Ma}$, respectively) (95\% HPD: 6.14-14.8/5.0-13.3, respectively) (Figure 1j). 

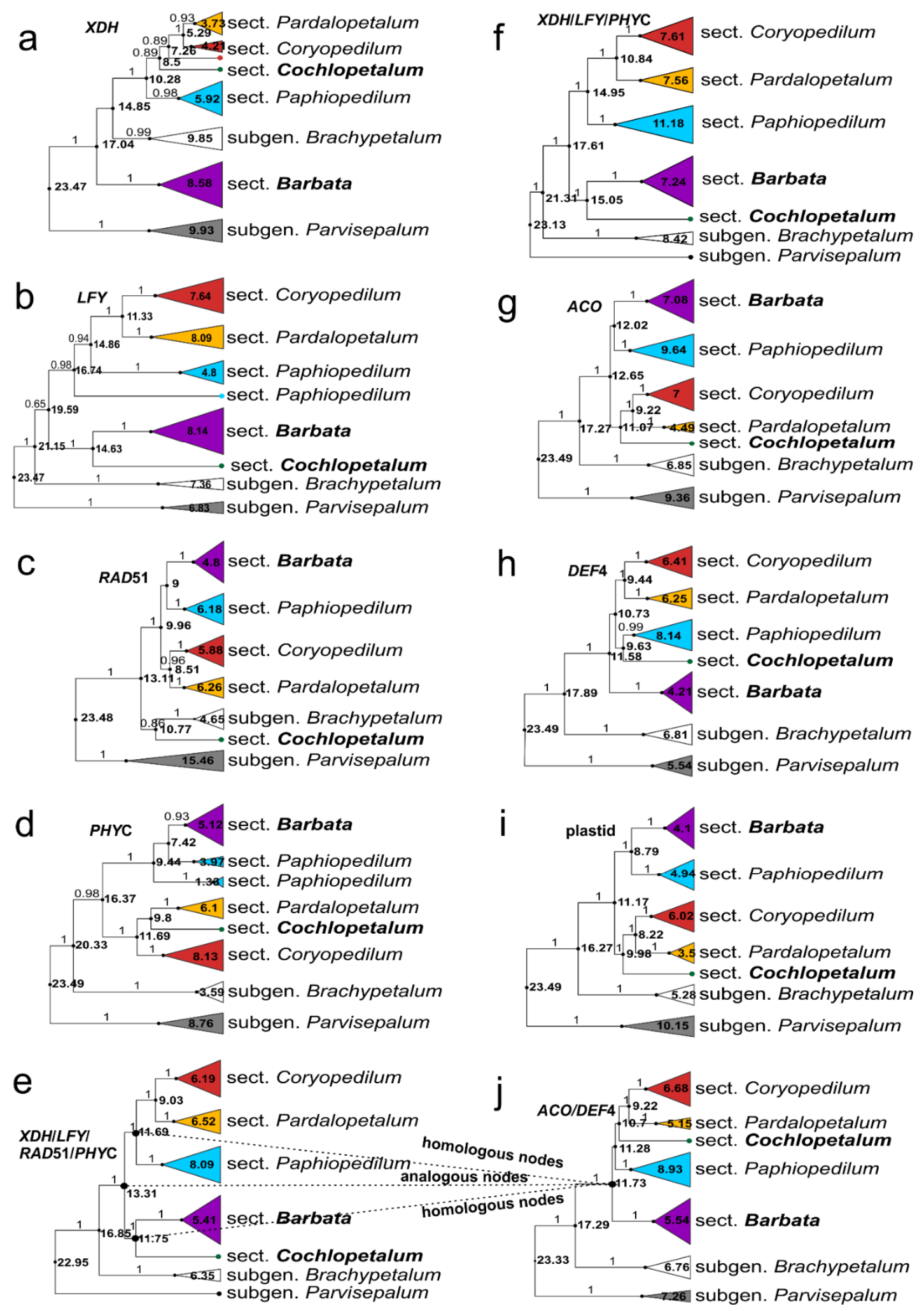

Figure 1. Time-calibrated gene trees of Paphiopedilum genus (maximum clade credibility trees) resulting from BEAST analysis of the nuclear data: (a)—XDH; (b)—LFY; (c)—RAD51; (d)—PHYC; (e)—combined XDH/LFY/RAD51/PHYC; (f)—combined XDH/LFY/PHYC; (g)—ACO; (h)—DEF4; (j)—ACO/DEF4; and (i)—plastid combined data. Posterior Probability (PP) values $>0.85$ are indicated above branches. Numbers at nodes are divergence times based on a strict (all except plastid and LFY trees) and relaxed (plastid and LFY) clock analysis. The names of taxa with conflicting positions are in bold type. Classification to clades follows Cribb [8]. 


\subsection{Molecular Phylogenetics and Network Analysis}

Concatenated analysis of all nuclear markers with modification of data matrices (as shown in Table 3) indicated that (1) subgenus Paphiopedilum was monophyletic and (2) single-flowered species (sections Barbata and Paphiopedilum) and multi-flowered species (i.e., sections Coryopedilum, Pardalopetalum, and Cochlopetalum) were monophyletic. All the internal nodes of the tree were supported by PP $=1.0$ (Figure 2). Network analysis using Bayesian MCMC_GT showed the same topology of the tree listed in a $95 \%$ credible set of topologies (percent $=53.94)$. In addition, eleven reticulation scenarios were detected. Two of the most probable networks $(\log =-13.19688, \log =-13.75276)$ are depicted in Figure 3.

Table 3. Combination of data partitions (nuclear-combined data matrix) and taxa used for phylogenetic analyses. Shaded boxes indicate sequences, and white boxes indicate excluded data ("missing data") in the matrix.

\begin{tabular}{|c|c|c|c|c|c|c|c|c|c|}
\hline Taxa/Markers & $A C O$ & DEF4 & PHYC & XDH_1 & XDH_2 & $L F Y \_1$ & $L F Y \_2$ & RAD51_1 & RAD51_2 \\
\hline Coryopedilum & & & & & & & & & \\
\hline Pardalopetalum & & & & & & & & & \\
\hline Cochlopetalum & & & & & & & & & \\
\hline Paphiopedilum & & & & & & & & & \\
\hline Barbata & & & & & & & & & \\
\hline Brachypetalum & & & & & & & & & \\
\hline Parvisepalum & & & & & & & & & \\
\hline
\end{tabular}

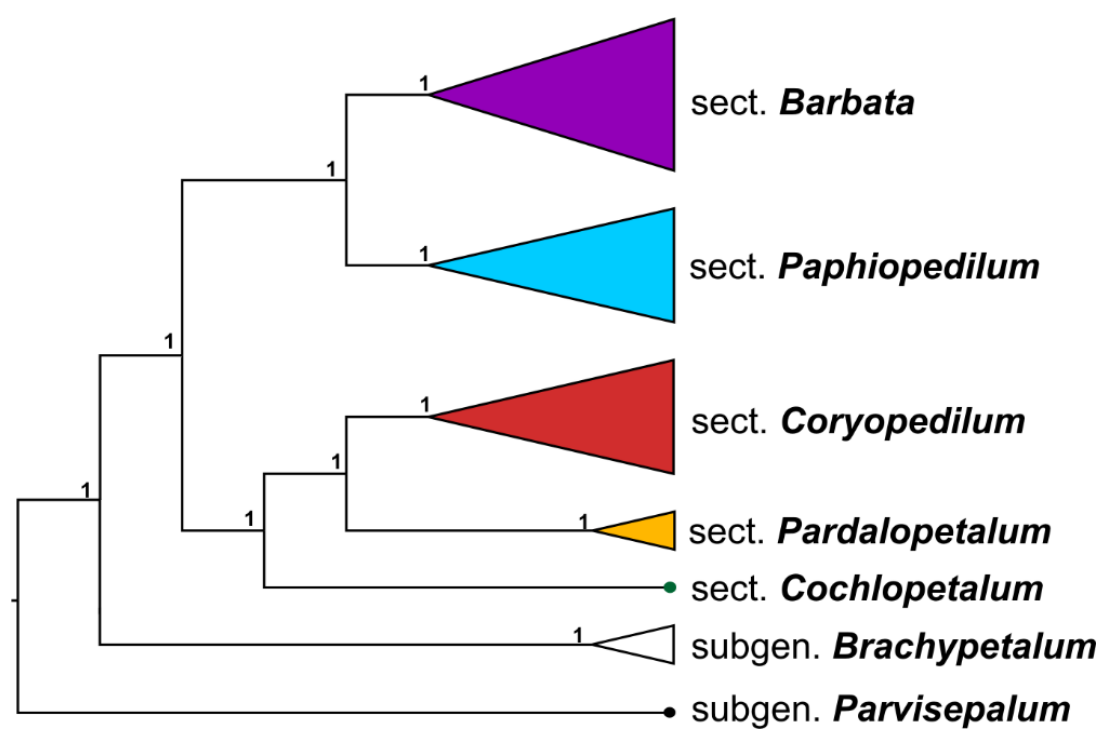

Figure 2. Nuclear gene tree of Paphiopedilum genus based on combined analysis of ACO/DEF4/PHYC/XDH_1/XDH_2/LFY_1/LFY_2/RAD51_1/RAD51_2 (see Table 3). PP values are indicated above branches.

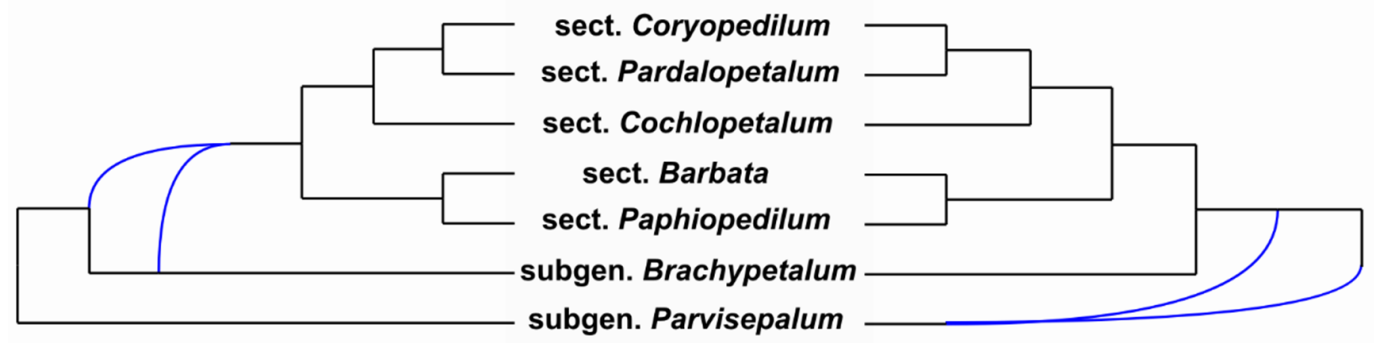

Figure 3. Two of the most probable Bayesian MCMC phylogenetic networks $(\log =-13.19688, \log =-13.75276)$ using gene tree topologies (nuclear-ACO,DEF4, PHYC, XDH, LFY, RAD51, and plastid tree). The Blue line indicates possible scenarios of hybridization. 


\section{Discussion}

\subsection{Molecular Dating}

Hitherto, none of the four low copy nuclear markers analyzed by Górniak et al. [15] and Guo et al. [16] showed a topology fully congruent with plastid and morphological analysis. Our results, based on the PHYC analysis, support the morphological data and confirm the existence of two evolutionary lineages within subgenus Paphiopedilum, the first of which includes the sections Barbata and Paphiopedilum, while the second one includes the multi-flowered species (i.e., sections Coryopedilum, Pardalopetalum, and Cochlopetalum).

Although gene duplication and ILS cannot be rejected as the reason for phylogenetic tree topology incongruence among the XDH, LFY, RAD51, and PHYC genes (Figure 1a-d), where the subgenus Paphiopedilum is concerned, ancestral hybridization is a more probable explanation, as well as a parsimonious one. The proof for this hypothesis lies in the phylogenetic trees based on the molecular clock and phylogenetic network analysis. Two groups of trees can be distinguished on the basis of the obtained results. The first group (ACO, DEF4, plastid DNA trees; Figure 1g-i) strongly supports (PP 1.0) the subgenus Paphiopedilum in its current circumscription and shows a strong division (only the plastid DNA analysis) into two groups corresponding to morphology. The tMRCA for subgenus Paphiopedilum, both for the plastid DNA and combined nuclear (ACO/DEF) analyses equals 11.17 Ma (95\% HPD: 6.8-16.3) and 11.7 Ma (95\% HPD: 9.1-14.6), respectively (Figure 1i,j). The divergence times of specific sections within the subgenus are also highly similar. The second group of trees ( $L F Y, R A D 51, X D H, P H Y C)$ (Figure 1d) does not support the monophyly of the subgenus on its own; however, the combined analysis shows a highly supported tMRCA of the subgenus Paphiopedilum of ca. 13.31 Ma (95\% HPD: 10.0-16.9) (Figure 1e). Although the value is only 2 million years higher, compared with the combined plastid and ACO/DEF4 genes analysis, it increases to 6 My when RAD51 is excluded from the analysis (Figure 1f). The nodes on the phylogenetic trees obtained from the analyses of the combined XDH/LFY/RAD51/PHYC (Figure 1e) and ACO/DEF4 (Figure 1j) matrices referring to MRCA of the subgenus Paphiopedilum are "analogous" in the case of both analyses (Figure 1e,j). The difference within the time scale of these nodes stems from the analysis of one (plastid genome, $A C O, D E F 4$ ) (Figure 4a) or both parental alleles (XDH, LFY, RAD51, PHYC) (Figure $4 \mathrm{~b}, \mathrm{c})$. On the other hand, the nodes resulting from the same speciation event (the "homologous nodes") refer to different terminal taxa (Figure 1e,j). We believe that the tMRCA of the Paphiopedilum subgenus, calculated on the basis of the XDH/LFY/RAD51/PHYC matrix, does not refer to the ancestor of the subgenus Paphiopedilum but to a proto-Paphiopedilum ancestor (subgenus Paphiopedilum) from before the hybridization event. It seems that ancestral hybridization that gave rise to a new evolutionary lineage (hybrid origin) that subsequently diversified may be interpreted as ILS. 
Species tree

a

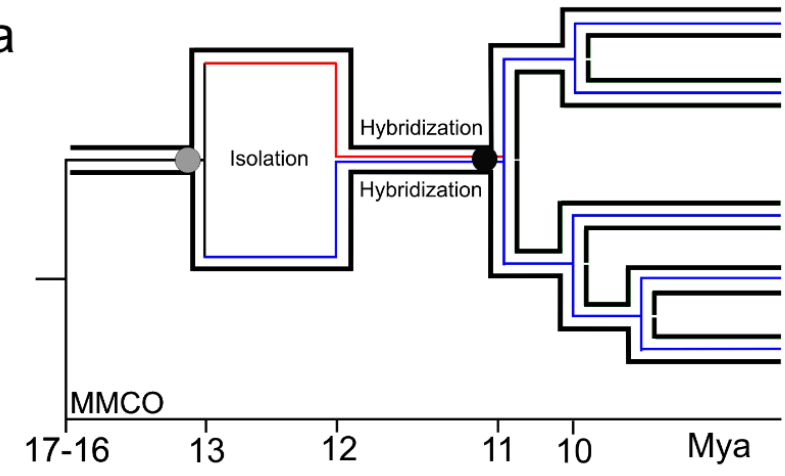

Paphiopedilum

Barbata

Cochlopetalum

Pardalopetalum

Coryopedilum

Brachypetalum
Gene tree

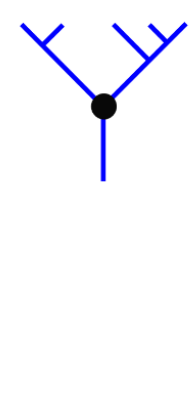

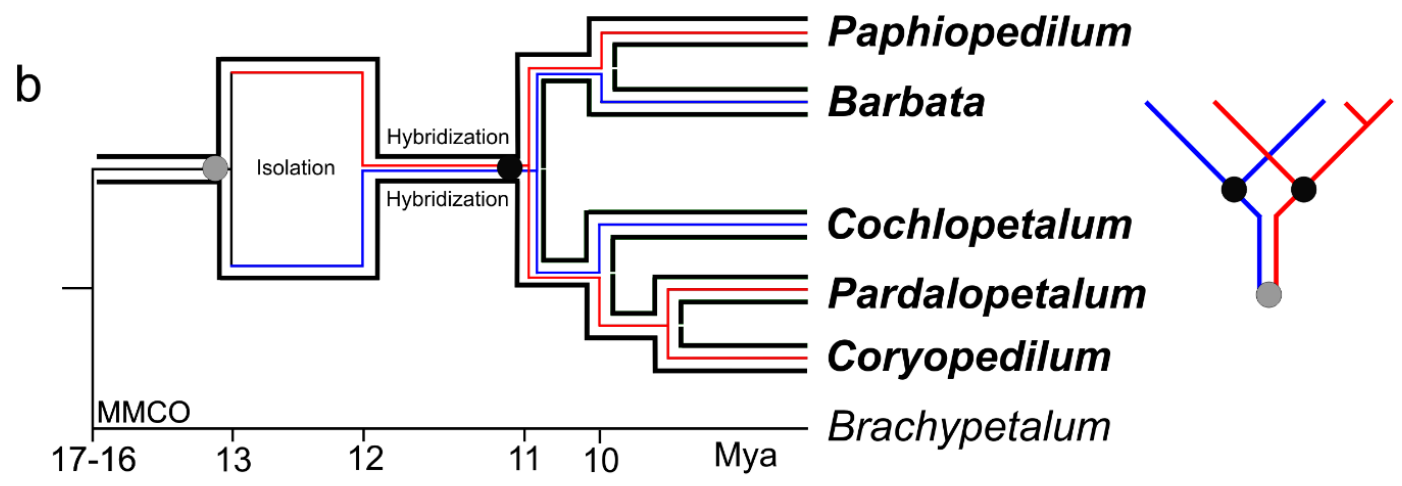
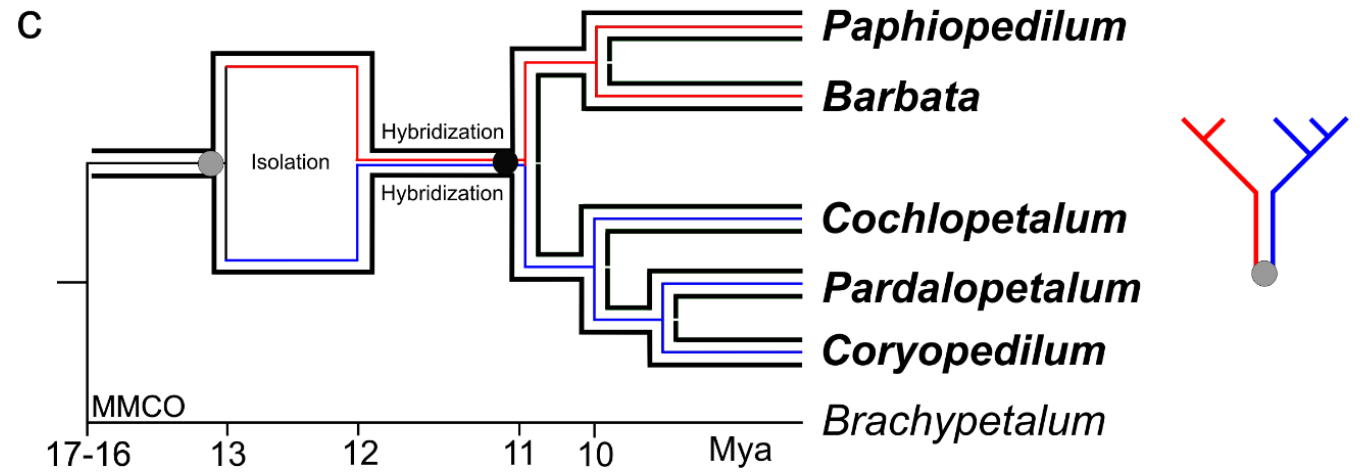

Figure 4. The species tree (black line) on which plastid gene tree (a), nuclear gene trees LFY (b), and PHYC (c) were applied. The illustration explains the reason for conflicts between gene trees and species trees within the subgenus Paphiopedilum. MMCO is the Mid-Miocene Climatic Optimum. Blue and red lines represent different gene copies (alleles/haplotypes) that diverged as a result of isolation/speciation. For the plastid gene tree, it was assumed that, after the hybridization process, only one haplotype remained (a). The nuclear gene tree for PHYC (c) and the plastid gene tree (a) have identical topology but different nodes with respect to their MRCA—a proto-Paphiopedilum subgenus (gray node) and Paphiopedilum subgenus (black node), respectively. The gene trees for $L F Y(\mathbf{b})$ and for $P H Y C$ (c) have different topologies but the same node with respect to their MRCA (gray node).

\subsection{Geological: Climate Changes through Miocene}

According to Hall [18], between 60 and 5 million years ago (Neogene era) the Sunda Shelf area was above sea level, thus making migration of plants from continental Asia 
to Borneo theoretically possible. In such a scenario, climate may have served as a migration limiting factor [19]. The early and middle Miocene epoch was wet and warm, with rainforest across Sundaland [20]. Southward migration from continental Asia to Sundaland during the Miocene period has been documented for many plant species, e.g., Lithocarpus (Fagaceae) [21], Pseuduvaria (Annonaceae) [22], Begonia (Begoniaceae) [23], and Alocasia (Araceae) [24]. A decline in the sea level enabled a periodic exchange of organisms between regions that were otherwise isolated. Based on geological reconstructions and palynological analyses, de Bruyn et al. [25] concluded that Miocene flora and fauna were divided between two regions: the northern (Indochina) and the southern (Borneo) parts of the Thai-Malay Peninsula, within the mid-Miocene climatic optimum (MMCO), approximately 17-15 Ma [26] or 16-14 Ma [27]. Interestingly, this period correlates closely with the Brachypetalum/proto-Paphiopedilum subgenus divergence time of 16-17 Ma (Figure 1e,h,i,j). Diversification of proto-Paphiopedilum subgenus into two subpopulations and species formation could have stemmed from geographic isolation generated by a sudden water level rise, which occurred approximately 13.8 Ma (the Serravallian Stage) [20]. Hybridization of both lineages (species/divergent populations) had to occur more than 11 million years ago. Afterward, rapid radiation of the subgenus Paphiopedilum could have caused differentiation into five sections. Each of the sections is highly diversified morphologically [8], and it seems highly probable that they also arose in geographical isolation within the period of strong ocean level fluctuations in the mid-Miocene, about 10-11 Ma (Figure 1). This time agrees with several significant sea-level fluctuations that occurred in the Miocene epoch. Sea levels declined during the Serravallian Stage (at 13.8 Ma, 12.8 Ma, $11 \mathrm{Ma}$ ), and during the late Miocene (the earliest Tortonian), it was at $-90 \mathrm{~m}$ [20]. Guo et al. [16] and Tsai et al. [28] proved that sea-level fluctuations had an impact on the evolution of Paphiopedilum. Both authors $[16,28]$ indicate that in situ speciation within islands accelerated species divergence in the subgenus Paphiopedilum. This rapid radiation can also be supported by the unresolved tree topologies (polytomy) of the markers that originate from one parental lineage ( $A C O, D E F 4$, and individual plastid markers). However, we considered, taking into account our analysis, that the shift of speciation rate in the subgenus Paphiopedilum was preceded by the hybridization process. There are, however, many indications in favor of hybridization being a factor contributing to nuclear tree topology inconsistencies with regard to the subgenus Paphiopedilum. These symptoms are observed on many levels, such as species diversification, genome rearrangement, and geographic distribution. The subgenus Paphiopedilum comprises about 60 species, compared with 4 and 5 species for 2 other subgenera, Brachypetalum and Parvisepalum, respectively [8]. On the cytological level, the subgenus Paphiopedilum is also characterized by multiple duplications regarding 5S rDNA [29]. The geographic range of subgenera Parvisepalum and Brachypetalum is limited to southeast continental Asia. Subgenus Paphiopedilum, with the exception of the section Paphiopedilum, also occupies the islands of the Malaysian Archipelago, New Guinea, and the Solomon Islands.

\subsection{Post-Hybridization Scenario}

Processes stemming directly from hybridization might be the cause of the loss of alleles. Müntzing [30] postulated that sorting of chromosomal rearrangements in latergeneration hybrids could, by chance, lead to the formation of new populations that were homozygous for a unique combination of chromosomal sterility factors and were partially reproductively isolated from both parental species. Stebbins [31] and Grant [32] proposed a model of homoploid hybrid speciation where two parental species are distinguished by two or more separable chromosomal rearrangements. This leads through a partially sterile hybrid stemming from segregation and recombination to new homozygous recombinant types [33]. This means that even a whole chromosome of one of the two parents could very quickly be lost in a hybrid population. Folk et al. [34] show that after the crossing-over, fertile hybrids in generation $\mathrm{F}_{2}$ will be heterozygotes carrying recombined chromosomes. After several generations, sorting or coalescence of all parental alleles may occur. The 
effect will be a mosaic of parental genomes. Folk et al. [34] call the divided fragments of chromosomes of the same evolutionary history "h-genes" (from the hybrid event). If the aforementioned processes had occurred before the differentiation of two evolutionary lineages (single- and multi-flowered), trees of the nuclear genes should correspond to the species tree since they will not show the ancestral hybridization due to carrying the same ancestral copy inherited from only one of the parents. In other words, differentiation and genetic distance should be consistent with the speciation processes that occurred within the subgenus Paphiopedilum. Such a process is shown in Figure 4a. In our analyses, this applied to plastid and nuclear $A C O$ and DEF4 genes. Lack of topology/divergence time conflict among the plastid DNA suggests unidirectional hybridization, which is common in the family Orchidaceae [35]. If both parental alleles had survived in the gene pool after the hybridization event and were introduced to the populations of the multi-flowered section ancestor, as well as the Barbata and Paphiopedilum sections ancestor, they could have entered different sections randomly during divergence (Figure $4 b$ ). This process would have resulted in phylogenetic gene trees being incongruent with the species tree obtained on the basis of nuclear DNA analysis, which would support different tree topologies referring to various sections of the subgenus Paphiopedilum. In this case, only sections Barbata and Cochlopetalum would be in conflict. It is worth noting that both of these sections carry a higher than the basic (plesiomorphic) number of chromosomes. The question remains whether the decomposition of chromosomes observed independently in representatives of sections Barbata and Cochlopetalum stems from inheriting a particular set of genes/chromosomes after hybridization that had to be decomposed due to their incompatibility. The third possible scenario is represented by the PHYC gene analysis. The PHYC gene, in turn, corresponds with the analysis of the plastid DNA/morphology; however, we also believe it to have resulted from a random distribution of two parental alleles to each of the populations, but in accordance with speciation processes that occurred after the hybridization process (Figure 4c).

\subsection{Reconstruction of the Phylogeny}

Conducting a combined phylogenetic analysis with conflicted markers is a difficult challenge. Usually, the incongruent nodes are removed before the combined analysis is carried out. Unfortunately, this eliminates the possibility to determine the phylogenetic relationships of the conflicted taxa. In the case of a conflict between two sets of markers (e.g., cpDNA vs. nrDNA), in order to show the hybridization, a taxon is duplicated, with plastid-only accession remaining in one set (nrDNA characters coded as missing) and nrDNA-only accession in the other (plastid characters coded as missing) [36]. As a result, a phylogenetic location obtained from various markers is shown on one tree [36]. In our analysis, two other approaches were implemented in order to determine the phylogenetic relationships within the genus Paphiopedilum. The first one was based on phylogenetic network analysis using Bayesian MCMC from gene tree topologies. The second one comprised a combined analysis of the nuclear markers according to the presented scheme in spite of their topology conflicts (Table 3). The results of both analyses are identical and consistent with the morphological hypothesis and the plastid DNA analysis. Moreover, the network analysis confirmed the assumption of ancestral hybridization being the reason for the conflict of various marker topologies (Figure 3). A precise description of the subgenus phylogeny is complicated by the mosaic genotype setup of the ancestral populations of each of the sections, divided randomly among them. Only a process of revealing a large portion of the whole genomes would make it possible to finally determine the relationships. In our work, we indicated how these relationships will appear as.

\section{Materials and Methods}

\subsection{DNA Isolation, Amplification, and Sequencing}

DNA from representatives of Cypripedioideae was extracted from 27 species (Supplementary Table S2). Genomic DNA was extracted from $20 \mathrm{mg}$ of specimens (parts of leaves) 
dried in silica-gel [37] using a DNA Mini Plant Kit (A\&A Biotechnology, Poland). Descriptions of laboratory procedures such as primers used, specific conditions for polymerase chain reaction (PCR), purification, and sequencing for low-copy $\mathrm{XDH}$ and plastid matK genes were given in a separate paper [15]. Low-copy nuclear gene PHYC was amplified using PHYC_F (5'GTTYCATGARGATGAGCATGG3') and PHYC_R (5'GCTCCTCCCCAYTTGATTTC $^{\prime}$ ) primers designed specifically for this study. The PCR reaction was performed using Dream Taq PCR Master Mix (2x) (Thermo Scientific). In cases where heterogeneity of nucleotides was observed, an additional step of DNA cloning was conducted using the pJET 1.2 vector (Thermo Scientific CloneJET PCR Cloning Kit). Competent cells were obtained using Escherichia coli MC1061 [38] and calcium chloride. PCR amplification was performed using pJET1.2_F and pJET1.2_R primers, included in the kits. The High-Pure PCR Product Purification Kit (Roche Diagnostic GmbH, Germany) was used for the purification of PCR products, in accordance with the protocol specified by the manufacturer. The sequencing procedure was performed using the Big Dye Terminator v3.1 Cycle Sequencing Kit (Applied Biosystems, ABI, Warrington, Cheshire, UK), with the same primers as for the amplification step. GenBank accession numbers are presented in Supplementary Table S2.

\subsection{Molecular Phylogenetic and Time Divergence Analysis}

All sequences, except for PHYC and several of matK (11 sequences) and XDH (10 sequences), were downloaded from GenBank (Supplementary Table S2). To estimate the tMRCA for Paphiopedilum, representatives of all Cypripedioideae genera (Paphiopedilum, Phragmipedium, Mexipedium, Cypripedium, and Selenipedium) were used in the analysis. The Bayesian strict molecular clock approach implemented in BEAST v. 1.8.1 [39] was used for $m a t K, P H Y C$, and XDH matrices and combined analysis. The age for the root of the tree (Cypripedioideae) was set to a normal prior distribution with a mean of $64 \mathrm{Ma}$ and a standard deviation of 4.0 to the resulting age estimated for Cypripedioideae based on the analysis of matK+rbcL [40]. The original calibration point source was based on Ramirez et al. [41]. Trees are provided in Supplementary Figures S1-S4. Based on this analysis, the prior age parameter for the tMRCA for Paphiopedilum clade (the root of the tree) was set to $24 \mathrm{Ma}$ with normal distribution and a standard deviation of 2.0. Six different lowcopy nuclear genes (ACO,DEF4, XDH, LFY, RAD51, and PHYC) and a combined plastid matrix (ycf1, atpI-atpH, trnL-trnF, atpF-atpH, $r p o C 2, a c c D, r b c L$, and matK) were analyzed. In Addition, two combined nuclear data sets were created based on topologies of previously published trees $[15,16]$ and those of this study $(P H Y C)$, which were used in the analysis. These are as follows: the monophyly matrix markers ACO/DEF4 (which strongly support subgenus Paphiopedilum, but do not resolve relationships within the subgenus-polytomy that occurred); and the non-monophyly matrix markers XDH/LFY/RAD51/PHYC (subgenus Paphiopedilum is not supported by PP and topologies of the trees based on these markers are incongruent with each other). The aim of the latter analysis was to check whether the concatenated matrix of the above markers also supports the monophyletic character of the subgenus Paphiopedilum. Sequence alignments were obtained using Mafft v. 7 [42] and then analyzed by SeaView v. 4.7 [43]. The Bayesian strict molecular clock (for nuclear data) and the uncorrelated relaxed molecular clock (for combined plastid data) approaches implemented in BEAST v. 1.8.1 [39] were used. For all data matrices, the birth-death process [44] was chosen as the speciation process. Two runs were performed in BEAST, with 20 million generations each and a sampling frequency of 1000 . The $\mathrm{Mr}-$ Modeltest v. 2 [45] was used in order to choose the best-fitting evolutionary model by the Akaike Information Criterion. Tracer v. 1.6 [46] was used to analyze Log files to assess the convergence. The combined effective sample sizes for all the chosen parameters were larger than 200. All the obtained trees were combined with LogCombiner v. 1.8.1 [39], with a burn-in of $25 \%$. Finally, the maximum credibility tree was produced using TreeAnnotator v. 1.8.1 [39]. The molecular clock was chosen based on the Bayes factor $\left(2 \log _{e}(B F)\right)$ using the marginal likelihoods of the model estimated using the stepping-stone/path-sampling methods in BEAST v. 1.8.1 [39]. Evidence against the null model, which is the one with 
lower marginal likelihood, was estimated based on Kass and Raftery [47]. For the analysis, $2>2 \log _{e}(\mathrm{BF})>6$ indicates positive evidence against the null model; $6>2 \log _{\mathrm{e}}(\mathrm{BF})>$ 10 indicates strong evidence against the null model; $2 \log _{\mathrm{e}}(\mathrm{BF})>10$ indicates very strong evidence against the null model.

\subsection{Phylogenetic Network Analysis}

The small data matrix (one species from each section) was created and analysed using MrBayes v. 3.2.5 [48]. The posterior probabilities of clades were estimated by sampling trees from the PP distribution using Markov chain Monte Carlo (MCMC) simulations. Six chains were run for 10,000,000 generations. Trees were sampled every 100 generations. The first 25,000 trees were discarded as the burn-in samples. The remaining trees were used to assess topology, PPs, and gene tree distributions. The internal nodes with PP lower than 0.97 in gene trees analysis were collapsed: $[X D H]-(((A, B),(\mathrm{C}), \mathrm{E}),(\mathrm{D}),(\mathrm{F})), \mathrm{G}) ;[\mathrm{RAD} 51]-$ $(((\mathrm{F}, \mathrm{C}),((\mathrm{A}),(\mathrm{B}),(\mathrm{E}),(\mathrm{D}))), \mathrm{G}) ;[P H Y \mathrm{C}]-((\mathrm{F},((\mathrm{B}),(\mathrm{A}),(\mathrm{C})),(\mathrm{E}, \mathrm{D}))), \mathrm{G}) ;[A C O]-((\mathrm{F},((\mathrm{A}, \mathrm{B}), \mathrm{C})$, $(\mathrm{E}),(\mathrm{D}))), \mathrm{G}) ;[\mathrm{DEF} 4]-((\mathrm{F},((\mathrm{A}, \mathrm{B}),(\mathrm{C}),(\mathrm{E}),(\mathrm{D}))), \mathrm{G}) ;[L F Y]-((\mathrm{F},(\mathrm{A}, \mathrm{B}),(\mathrm{E}),(\mathrm{C}, \mathrm{D})), \mathrm{G}) ;$ and [Plastid] $((\mathrm{F},((\mathrm{A}, \mathrm{B}), \mathrm{C}),(\mathrm{E}, \mathrm{D}))), \mathrm{G})$. These were used as input trees in MCMC_GT analysis in PhyloNet software v. 3.8.0 [49,50]. Nodes presented in Newick format were as follows: A-sect. Coryopedilum; B-sect. Pardalopetalum; C—sect. Cochlopetalum; D—sect. Barbata; E-sect. Paphiopedilum; F-subgen. Brachypetalum; and G—subgen. Parvisepalum. MCMC_GT infers phylogenetic networks using Bayesian MCMC from gene tree topologies using a multispecies network coalescent framework (MSNC) [51]. MSNC incorporates hybridization in addition to incomplete lineage sorting (ILS). The length of the MCMC chain was 2,000,000 with 200,000 of iterations in burn-in period. The sample frequency was 1000 . The maximum number of reticulation nodes in the sampled phylogenetic networks was the default value-infinity. Network/Trees generated by PhyloNet were visualized by Dendroscope v. 3.6.3 [52].

\subsection{Using Nuclear Genes for Inferring Phylogeny}

All six nuclear genes were concatenated into one matrix. Data matrices for $A C O$, DEF4 (which strongly support subgenus Paphiopedilum but do not resolve relationships within the subgenus), and PHYC (which supports Paphiopedilum subgenus only moderately and resolves the relationships within the subgenus-congruent with plastid phylogeny) were used without any modifications. Data matrices for XDH, LFY, RAD51 (topology incongruence concerns the entire sections-Barbata and Cochlopetalum) were duplicated, and some taxa (representing entire sections) were deleted, as shown in Table 3. The taxa removed from one submatrix were used in the other one, and vice versa. For example, in the case of the LFY matrix sections, Barbata and Cochlopetalum are sister groups. This relationship is inconsistent with both morphological and plastid DNA analyses. In such a case, the representatives of both sections were removed from one submatrix, while all of the remaining sections' representatives (Pardalopetalum, Coryopedilum, and Paphiopedilum) were removed from the other copy. As a result, all of the data (sequences) were used in the analysis. Brachypetalum and Parvisepalum subgenera representatives were included in both matrices. During the analyses, we assumed that the topology conflicts stem from ancestral hybridization/ILS/genome duplication, and a specific cause is unimportant. The goal of the analyses was to obtain the species phylogeny in spite of the topology incongruence of the particular phylogenetic gene trees. Therefore, a matrix modified in this way (see Table 3) was subjected to Bayesian inference in MrBayes v. 3.2 .5 [48] for inferring the phylogeny of the genus Paphiopedilum. The analysis was performed as described in Section 4.3.

Supplementary Materials: The following are available online at https:/ /www.mdpi.com/article/10 $.3390 /$ ijms222111393/s1.

Author Contributions: Conceptualization, M.G., D.L.S. and M.S.Z.; data curation, M.G. and A.M.N.; formal analysis, M.G.; investigation, M.G., N.O., A.M.N. and L.B. methodology, M.G., N.O., A.M.N., 
A.M. and L.B.; project administration, M.G.; resources, D.L.S.; supervision, M.G., D.L.S. and M.S.Z.; validation, M.G., D.L.S. and M.S.Z.; visualization, M.G., N.O., A.M.N. and A.M.; writing-original draft preparation, M.G. All authors have read and agreed to the published version of the manuscript.

Funding: This research was funded by the Polish Ministry of Science and Higher Education (Project No. NN 303 294034). The APC was funded by the University of Gdańsk.

Institutional Review Board Statement: Not applicable.

Informed Consent Statement: Not applicable.

Data Availability Statement: Data matrices are available online at https://doi.org/10.6084/m9 .figshare.16577810 (last accessed on 22 October 2021).

Acknowledgments: We would like to express our sincere gratitude to Karol Błaszczak for his support in editing the manuscript and providing English translation and the two anonymous referees for valuable comments improving the manuscript.

Conflicts of Interest: The authors declare no conflict of interest. The funders had no role in the design of the study; in the collection, analyses, or interpretation of data; in the writing of the manuscript, or in the decision to publish the results.

\section{References}

1. Rieseberg, L.H.; Ellstrand, N.C.; Arnold, M. What Can Molecular and Morphological Markers Tell Us About Plant Hybridization? Crit. Rev. Plant Sci. 1993, 12, 213-241. [CrossRef]

2. Maddison, W.P. Gene Trees in Species Trees. Syst. Biol. 1997, 46, 523-536. [CrossRef]

3. Frajman, B.; Eggens, F.; Oxelman, B. Hybrid Origins and Homoploid Reticulate Evolution within Heliosperma (Sileneae, Caryophyllaceae) -A Multigene Phylogenetic Approach with Relative Dating. Syst. Biol. 2009, 58, 328-345. [CrossRef]

4. Maureira-Butler, I.J.; Pfeil, B.E.; Muangprom, A.; Osborn, T.C.; Doyle, J.J. The Reticulate History of Medicago (Fabaceae). Syst. Biol. 2008, 57, 466-482. [CrossRef]

5. Joly, S.; McLenachan, P.A.; Lockhart, P.J. A Statistical Approach for Distinguishing Hybridization and Incomplete Lineage Sorting. Am. Nat. 2009, 174, E54-E70. [CrossRef]

6. Yu, Y.; Than, C.; Degnan, J.H.; Nakhleh, L. Coalescent Histories on Phylogenetic Networks and Detection of Hybridization Despite Incomplete Lineage Sorting. Syst. Biol. 2011, 60, 138-149. [CrossRef]

7. Yu, Y.; Degnan, J.H.; Nakhleh, L. The Probability of a Gene Tree Topology within a Phylogenetic Network with Applications to Hybridization Detection. PLoS Genet. 2012, 8, e1002660. [CrossRef] [PubMed]

8. Cribb, P.J. The Genus Paphiopedilum, 2nd ed.; Natural History Publications (Borneo) in association with Royal Botanic Gardens; Kew: Kota Kinabalu, Malaysia, 1998.

9. Brieger, F.G.; Maatsch, R.; Senghas, R. Unterfamilie: Cypripedioideae in Die Orchideen; Schlechter, R., Ed.; Paul Parey: Berlin, Germany, 1971; pp. 161-185.

10. Karasawa, K.; Saito, K. A revision of the genus Paphiopedilum (Orchidaceae). Bull. Hiroshima Bot. Gard. $1982,5,1-69$.

11. Hennessy, E.F.; Cribb, P.; Mathew, B. The Genus Paphiopedilum. Kew Bull. 2000, 55, 249. [CrossRef]

12. Braem, G.J.; Baker, C.O.; Baker, M.L. The Genus Paphiopedilum-Natural History and Cultivation; Botanical Publishers: Kissimmee, FL, USA, 1998; Volume 2.

13. Braem, G.J.; Chiron, G. Paphiopedilum; Tropicalia: Lyon, France, 2003.

14. Chochai, A.; Leitch, I.J.; Ingrouille, M.J.; Fay, M.F. Molecular phylogenetics of Paphiopedilum (Cypripedioideae; Orchidaceae) based on nuclear ribosomal ITS and plastid sequences. Bot. J. Linn. Soc. 2012, 170, 176-196. [CrossRef]

15. Górniak, M.; Szlachetko, D.L.; Kowalkowska, A.K.; Bohdanowicz, J.; Canh, C.X. Taxonomic placement of Paphiopedilum canhii (Cypripedioideae; Orchidaceae) based on cytological, molecular and micromorphological evidence. Mol. Phylogenet. Evol. 2014, 70, 429-441. [CrossRef] [PubMed]

16. Guo, Y.-Y.; Luo, Y.-B.; Liu, Z.-J.; Wang, X.-Q. Reticulate evolution and sea-level fluctuations together drove species diversification of slipper orchids (Paphiopedilum) in South-East Asia. Mol. Ecol. 2015, 24, 2838-2855. [CrossRef] [PubMed]

17. Guo, Y.-Y.; Yang, J.-X.; Bai, M.-Z.; Zhang, G.-Q.; Liu, Z.-J. The chloroplast genome evolution of Venus slipper (Paphiopedilum): IR expansion, SSC contraction, and highly rearranged SSC regions. BMC Plant Biol. 2021, 21, 1-14. [CrossRef]

18. Hall, R. The palaeogeography of Sundaland and Wallacea since the Late Jurassic. J. Limnol. 2013, 72, e1. [CrossRef]

19. Morley, R.J. Palynological evidence for Tertiary plant dispersals in the SE Asian region in relation to plate tectonics and climate. In Biogeography and Geological Evolution of SE Asia; Hall, R., Holloway, D.J., Eds.; Backhuys: Leiden, The Netherlands, 1990; pp. 211-234.

20. Woodruff, D.S. Neogene marine transgressions, palaeogeography and biogeographic transitions on the Thai-Malay Peninsula. J. Biogeogr. 2003, 30, 551-567. [CrossRef]

21. Cannon, C.H.; Manos, P.S. Phylogeography of the Southeast Asian stone oaks (Lithocarpus). J. Biogeogr. 2003, 30, 211-226. [CrossRef] 
22. Su, Y.C.; Saunders, R.M. Evolutionary divergence times in the Annonaceae: Evidence of a late Miocene origin of Pseuduvaria in Sundaland with subsequent diversification in New Guinea. BMC Evol. Biol. 2009, 9, 153. [CrossRef]

23. Thomas, D.C.; Hughes, M.; Phutthai, T.; Ardi, W.H.; Rajbhandary, S.; Rubite, R.; Twyford, A.D.; Richardson, J.E. West to east dispersal and subsequent rapid diversification of the mega-diverse genus Begonia (Begoniaceae) in the Malesian archipelago. J. Biogeogr. 2011, 39, 98-113. [CrossRef]

24. Nauheimer, L.; Boyce, P.C.; Renner, S.S. Giant taro and its relatives: A phylogeny of the large genus Alocasia (Araceae) sheds light on Miocene floristic exchange in the Malesian region. Mol. Phylogenetics Evol. 2012, 63, 43-51. [CrossRef] [PubMed]

25. De Bruyn, M.; Stelbrink, B.; Morley, R.J.; Hall, R.; Carvalho, G.R.; Cannon, C.; Bergh, G.D.V.D.; Meijaard, E.; Metcalfe, I.; Boitani, L.; et al. Borneo and Indochina are Major Evolutionary Hotspots for Southeast Asian Biodiversity. Syst. Biol. 2014, 63, 879-901. [CrossRef] [PubMed]

26. Zachos, J. Trends, Rhythms, and Aberrations in Global Climate 65 Ma to Present. Science 2001, 292, 686-693. [CrossRef] [PubMed]

27. Song, Y.; Wang, Q.; An, Z.; Qiang, X.; Dong, J.; Chang, H.; Zhang, M.; Guo, X. Mid-Miocene climatic optimum: Clay mineral evidence from the red clay succession, Longzhong Basin, Northern China. Palaeogeogr. Palaeoclim. Palaeoecol. 2017, 512, 46-55. [CrossRef]

28. Tsai, C.-C.; Liao, P.-C.; Ko, Y.-Z.; Chen, C.-H.; Chiang, Y.-C. Phylogeny and Historical Biogeography of Paphiopedilum Pfitzer (Orchidaceae) Based on Nuclear and Plastid DNA. Front. Plant Sci. 2020, 11, 126. [CrossRef] [PubMed]

29. Lan, T.; Albert, V.A. Dynamic distribution patterns of ribosomal DNA and chromosomal evolution in Paphiopedilum, a lady's slipper orchid. BMC Plant Biol. 2011, 11, 126. [CrossRef] [PubMed]

30. Müntzing, A. Outlines to a genetic monograph of the genus galeopsis. Hereditas 1930, 13, 185-341. [CrossRef]

31. Stebbins, G.L. The hybrid origin of microspecies in the Elymus glaucus complex. Cytologia 1957, 36, 336-340.

32. Grant, V. The Regulation of Recombination in Plants. Cold Spring Harb. Symp. Quant. Biol. 1958, 23, 337-363. [CrossRef]

33. Buerkle, A.; Morris, R.J.; Asmussen, M.A.; Rieseberg, L. The likelihood of homoploid hybrid speciation. Heredity 2000, 84, 441-451. [CrossRef]

34. Folk, R.A.; Soltis, P.S.; Soltis, D.E.; Guralnick, R. New prospects in the detection and comparative analysis of hybridization in the tree of life. Am. J. Bot. 2018, 105, 364-375. [CrossRef]

35. Szlachetko, D.L.; Kolanowska, M.; Muller, F.; Vannini, J.; Rojek, J.; Górniak, M. First Guatemalan record of natural hybridisation between Neotropical species of the Lady's Slipper orchid (Orchidaceae, Cypripedioideae). PeerJ 2017, 5, e4162. [CrossRef]

36. Pelser, P.B.; Kennedy, A.H.; Tepe, E.; Shidler, J.B.; Nordenstam, B.; Kadereit, J.W.; Watson, L.E. Patterns and causes of incongruence between plastid and nuclear Senecioneae (Asteraceae) phylogenies. Am. J. Bot. 2010, 97, 856-873. [CrossRef] [PubMed]

37. Chase, M.W.; Hills, H.H. Silica gel: An ideal material for field preservation of leaf samples for DNA studies. TAXON 1991, 40, 215-220. [CrossRef]

38. Casadaban, M.J.; Cohen, S.N. Analysis of gene control signals by DNA fusion and cloning in Escherichia coli. J. Mol. Biol. 1980, 138, 179-207. [CrossRef]

39. Drummond, A.J.; Rambaut, A. BEAST: Bayesian evolutionary analysis by sampling trees. BMC Evol. Biol. 2007, 7, 1-8. [CrossRef] [PubMed]

40. Guo, Y.-Y.; Luo, Y.-B.; Liu, Z.-J.; Wang, X.-Q. Evolution and Biogeography of the Slipper Orchids: Eocene Vicariance of the Conduplicate Genera in the Old and New World Tropics. PLoS ONE 2012, 7, e38788. [CrossRef]

41. Ramírez, S.R.; Gravendeel, B.; Singer, R.B.; Marshall, C.R.; Pierce, N.E. Dating the origin of the Orchidaceae from a fossil orchid with its pollinator. Nature 2007, 448, 1042-1045. [CrossRef]

42. Katoh, K.; Standley, D.M. MAFFT Multiple Sequence Alignment Software Version 7: Improvements in Performance and Usability. Mol. Biol. Evol. 2013, 30, 772-780. [CrossRef]

43. Gouy, M.; Guindon, S.; Gascuel, O. SeaView Version 4: A Multiplatform Graphical User Interface for Sequence Alignment and Phylogenetic Tree Building. Mol. Biol. Evol. 2009, 27, 221-224. [CrossRef]

44. Gernhard, T. The conditioned reconstructed process. J. Theor. Biol. 2008, 253, 769-778. [CrossRef] [PubMed]

45. Nylander, J.A.A. MrModeltest v2. Program Distributed by the Author; Evolutionary Biology Centre, Uppsala University: Uppsala, Sweden, 2004.

46. Rambaut, A.; Drummond, A.J. Tracer v1.6. 2014. Available online: http:/ / beast.bio.ed.ac.uk/Tracer (accessed on 8 September 2021).

47. Kass, R.E.; Raftery, A.E. Bayes Factors. J. Am. Stat. Assoc. 1995, 90, 773-795. [CrossRef]

48. Ronquist, F.; Teslenko, M.; Van Der Mark, P.; Ayres, D.L.; Darling, A.; Hoehna, S.; Larget, B.; Liu, L.; Suchard, M.A.; Huelsenbeck, J.P. MrBayes 3.2: Efficient Bayesian Phylogenetic Inference and Model Choice Across a Large Model Space. Syst. Biol. 2012, 61, 539-542. [CrossRef] [PubMed]

49. Than, C.; Ruths, D.A.; Nakhleh, L. PhyloNet: A software package for analyzing and reconstructing reticulate evolutionary relationships. BMC Bioinform. 2008, 9, 322. [CrossRef] [PubMed]

50. Wen, D.; Yu, Y.; Zhu, J.; Nakhleh, L. Inferring Phylogenetic Networks Using PhyloNet. Syst. Biol. 2018, 67, 735-740. [CrossRef]

51. Wen, D.; Yu, Y.; Nakhleh, L. Correction: Bayesian Inference of Reticulate Phylogenies under the Multispecies Network Coalescent. PLoS Genet. 2017, 13, e1006598. [CrossRef] [PubMed]

52. Huson, D.H.; Scornavacca, C. Dendroscope 3: An Interactive Tool for Rooted Phylogenetic Trees and Networks. Syst. Biol. 2012, 61, 1061-1067. [CrossRef] 